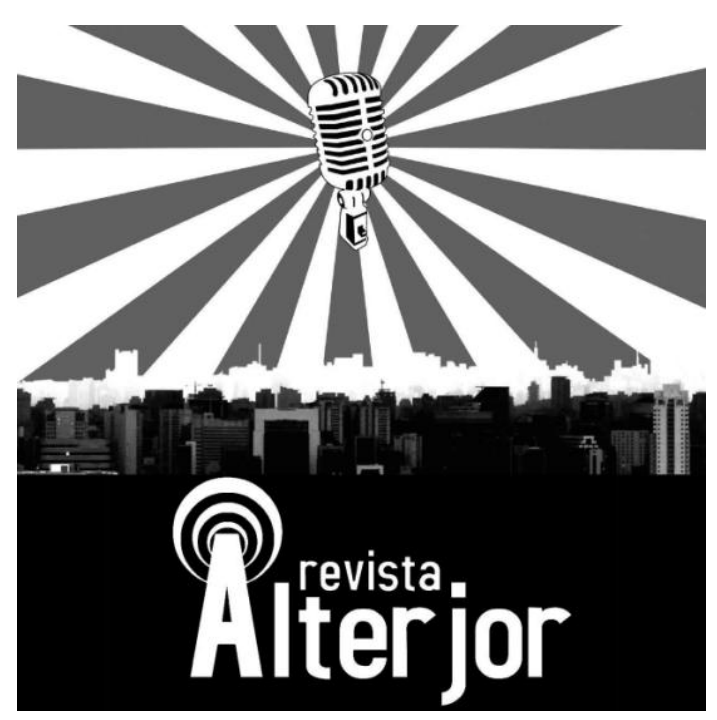

\title{
MUITO MAIS QUE YELLOWFACE: O INÍCIO DO RECONHECIMENTO ASIÁTICO
}

\author{
Mariana Moraes Nakamura ${ }^{1}$ \\ Simonetta Persichetti ${ }^{2}$
}

\begin{abstract}
RESUMO: O tema central do projeto é o de pesquisar sobre o conceito "yellowface" e a falta de representatividade de asiáticos em programas televisivos ocidentais. Essa pesquisa tem como objetivo principal encontrar soluções que possam responder ao questionamento do que faz com que os amarelos sejam representados, na maioria das vezes, de maneira rotulada e estereotipada, ou, até mesmo, não representados, como é o caso de várias produções midiáticas que representam o asiático de maneira caricata e ofensiva. Durante o período, alguns conceitos e autores foram abordados, como o de opinião pública por Walter Lippmann e o de estereótipo para Stuart Hall. Além desses citados, foi realizada uma análise das imagens do filme "Bonequinha de Luxo" a partir do conceito de estereotipo de Peter Burke; revisão bibliográfica no conceito de yellowface no cinema e definição do conceito de estereotipo a partir do conceito também de Peter Burke. Para finalizar, O livro de Serge Moscovici, Representações Sociais, me ajudou a entender representações sociais como meios de recriar a realidade.
\end{abstract}

PALAVRAS-CHAVE: Comunicação. Visualidade. Estereótipo. Yellowface. representatividade.

ABSTRACT: The central theme of the project is to research the concept of "yellowface" and the lack of representation of Asians in Western television programs. This research has as main objective to find solutions that can answer the question of what makes the yellow people to be represented, most of the time, in a labeled and stereotyped way, or even not represented, as is the case of several media productions. who represent the Asian in a caricature and offensive way. During the period, some concepts and authors were approached, such as public opinion by Walter Lippmann and stereotype for Stuart Hall. In addition to those mentioned, an analysis of the images of the movie "Breakfast at Tiffany's" was carried out based on Peter Burke's concept of stereotype; literature review on the concept of yellowface in cinema and definition of the concept of stereotype from Peter Burke's concept as well. Finally, Serge Moscovici's book, Social Representations, helped me to understand social representations as a means of recreating reality.

KEYWORDS: Communication; visuality; stereotype; yellowface; representativeness.

${ }^{1}$ Aluna da faculdade Cásper Líbero no curso de Relações Públicas, e-mail: mariana.nakamura@al.casperlibero.edu.br ${ }^{2}$ Orientadora da pesquisa. Doutora em psicologia pela PUC-SP (2001) e Pós-Doutora pela Escola de Comunicação e Artes, USP (2017). É professora de graduação e do programa de mestrado da faculdade Cásper Líbero na linha de pesquisa Jornalismo, Imagem e Entretenimento, e-mail: spersichetti@ casperlibero.edu.br

\section{Revista ALTERJOR}

Grupo de Estudos Alterjor: Jornalismo Popular e Alternativo (ECA-USP)

Ano 12 - Volume 01 - Edição 25 - Janeiro-Junho de 2022

Av. Professor Lúcio Martins Rodrigues, 443, Cidade Universitária, São Paulo, CEP: 05508-020 


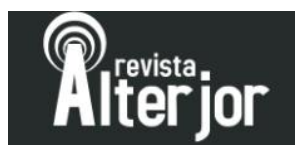

\section{INTRODUÇÃO}

O Óscar 2021 com certeza foi um marco para a luta asiática, quando se vê, em destaque, figuras do cinema asiático recebendo prêmios de grande renome para toda a sociedade. Yuh-Jung Youn, de Minari: Em Busca da Felicidade (2020) venceu o prêmio de melhor atriz coadjuvante e se tornou a segunda asiática a levar a estatueta da categoria em 93 anos de premiação. Em seu discurso de agradecimentos, a atriz trouxe uma brincadeira ácida: "Essa noite estou aqui e tenho um pouquinho mais de sorte que vocês talvez. Deve ser a hospitalidade americana para os coreanos". Outro ilustre acontecimento da noite, foi a estatueta dourada para uma diretora mulher e chinesa. Chloé Zhao ganhou o Oscar de melhor direção na noite por "Nomadland", o que a fez a segunda mulher na história do Oscar a vencer nessa categoria e a primeira diretora de uma minoria racial a levar uma estatueta.

Levando em consideração toda a trajetória da premiação, até o ano de 2019, apenas uma artista amarela foi agraciada na categoria de atuação, a japonesa Miyoshi Umeki, vencedora do Oscar de Melhor Atriz Coadjuvante em 1957, por Sayonara (Idem, 1957). Contudo, não houve mais convites para Miyoshi brilhar em outras longasmetragens. Neste mesmo filme, o qual possibilitou uma atriz asiática a ganhar o prêmio, contraditoriamente houve o uso de pesadas (e caricatas) maquiagens, a chamada "yellowface", na qual atores brancos interpretam asiáticos. No caso de Sayonara, Ricardo Montalban apareceu interpretando um japonês.

Já em outra categoria, de melhor diretor, quatro receberam indicação ao Oscar e apenas dois levaram a estatueta dourada para casa, não levando em consideração a premiação de Melhor Filme Estrangeiro). São eles, os japoneses Hiroshi Teshigahara (1964) e Akira Kurosawa (1985), Ang Lee, nascido em Taiwan, indicado três vezes, e vencedor do prêmio em duas ocasiões (2005 e 2012) e mais recentemente o sul-coreano, diretor e vencedor do prêmio pelo longa-metragem, Parasita, Bong Joon-ho (2020). Em relação ao sucesso de Parasita, ele se tornou o primeiro filme a conquistar os prêmios de melhor filme internacional, melhor diretor, melhor roteiro original e melhor filme, sendo a primeira produção não falada em inglês a levar o Oscar de melhor filme. Na cerimônia, o diretor do filme discursou a favor da diversidade no universo cultural:

Revista ALTERJOR

Grupo de Estudos Alterjor: Jornalismo Popular e Alternativo (ECA-USP)

Ano 12 - Volume 01 - Edição 25 - Janeiro-Junho de 2022

Av. Professor Lúcio Martins Rodrigues, 443, Cidade Universitária, São Paulo, CEP: 05508-020 


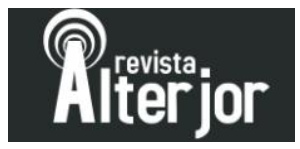

"Quando vocês superarem a minúscula barreira das legendas, vocês serão apresentados a muitos outros filmes incríveis."

Contudo, pode-se perceber que desde sua primeira cerimônia realizada, em 1929, o Oscar com 92 edições, teve somente dois prêmios destinados a atrizes asiáticas e três destinados a diretores asiáticos. Contabilizando cinco prêmios para asiáticos, enquanto a franquia mais premiada de Hollywood, $O$ senhor dos Anéis, soma 18 estatuetas. Dessa forma, é de suma importância notar a falta de representatividade asiática no âmbito cinematográfico para, também, percebê-la em diversos outros ambientes e os motivos para essa disparidade.

Para a realização desse artigo, tive como objetivo trazer enfoque a um tema pouquíssimo abordado e conhecido, além da curiosidade de sanar minhas próprias dúvidas e indagações em relação ao tema. Contudo, nas justificativas tive a minha ascendência nipônica como motivadora, a qual me faz sentir na pele as microagressões que envolvem esse cenário. Por meio de uma base qualitativa, de natureza interpretativa, como modalidade de abordagem metodológica, que, por meio de uma pesquisa documental e bibliográfica, foi realizada uma análise da representação asiática em programas de TV: no filme Bonequinha de Luxo (Breakfast at Tiffany's 1961) e na novela global Sol Nascente, de 2012.

Durante o período, alguns conceitos e autores foram abordados, como o de opinião pública por Walter Lippmann e o de estereótipo para Stuart Hall. Além desses citados, foi realizada uma análise das imagens do filme a partir do conceito de estereotipo de Peter Burke; revisão bibliográfica no conceito de yellowface no cinema e definição do conceito de estereotipo a partir do conceito também de Peter Burke. Para finalizar, O livro de Serge 3 Moscovici, Representações Sociais, me ajudou a entender representações sociais como meios de recriar a realidade.

\section{ESTEREÓTIPO}

Com isso, é necessário estudar os fenômenos por trás do estereótipo e como ele fortalece a compreensão de símbolos para a sociedade. Segundo o autor Lippmann, os estereótipos são padrões de comportamentos estabelecidos culturalmente. Graças aos

Revista ALTERJOR

Grupo de Estudos Alterjor: Jornalismo Popular e Alternativo (ECA-USP)

Ano 12 - Volume 01 - Edição 25 - Janeiro-Junho de 2022

Av. Professor Lúcio Martins Rodrigues, 443, Cidade Universitária, São Paulo, CEP: 05508-020 


\section{Ritieior}

estereótipos podemos atribuir significados aos acontecimentos sociais. os estereótipos são necessários para a coesão social, pois, por meio deles, significados comuns são compartilhados.

Por outro lado, os estereótipos também cumprem uma função integrativa de nossa experiência. Isso se dá porque temos inúmeras limitações de acesso aos fatos, tais como restrições de tempo para realizar uma investigação pessoal ou o distanciamento dos acontecimentos sociais. Vivemos em uma realidade complexa e o ser humano tem uma necessidade natural de dar sentido às coisas e às suas experiências. Os estereótipos, então, permitem que as pessoas tenham a sensação de compreensão da realidade, ainda que os juízos não tenham base empírica sólida. Como consequência disso, grande parte do que entendemos ser uma interpretação precisa da realidade não passa de uma construção meramente mental. Lippmann chama essa realidade ficcional, baseada em estereótipos, de pseudo ambiente.”

Ademais, as empresas de comunicação vivem de lucro. Por isso, elas têm de transmitir a informação de forma simples e compacta para torná-la compreensível e, assim, atrair a atenção do público a fim de manter o interesse dos anunciantes. Dessa forma, a imprensa reforça os estereótipos e potencializa os pseudoambientes. Portanto, mais informação não significa, necessariamente, maior esclarecimento e, por consequência, o aperfeiçoamento da democracia. Lippmann chega a anunciar que a imprensa dá apenas a notícia, sinalizando a ocorrência de um fato, sem transmitir, entretanto, a verdade.

"Os retratos dentro das cabeças dos seres humanos, retratos deles mesmos, dos outros, das suas necessidades, propósitos são suas opiniões públicas. Aqueles retratos que são adotados por grupos de pessoas, ou por indivíduos agindo em nomes de grupos, são Opinião Pública com letras maiúsculas.” Para Lippmann, a opinião pública se resume a um amontoado de retratos mentais que uma sociedade, após muitos processos, aceita como verdadeiros. Esses retratos nada mais são do que estereótipos. 


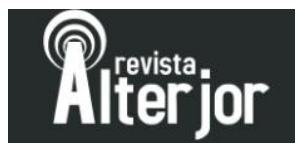

\section{HISTORICIDADE DO PRECONCEITO}

Costurando o estudo social dos estereótipos, pode-se notar a expressiva presença deles ao se tratar de preconceito. Nesse artigo, vamos discutir a respeito da historicidade do preconceito aos povos amarelos. É possível citar inúmeros acontecimentos durante a história, nos quais, esses povos foram expulsos, torturados, presos e violentados simplesmente por serem diferentes, como foi o caso da Lei da expulsão Chinesa em 1879 na Califórnia, a qual proibia qualquer indivíduo de ascendência chinesa viver em solo norte-americano. Outro acontecimento foi a criação de campos de concentração para japoneses, também nos Estados Unidos, durante o período da Segunda Guerra Mundial (1939-1945), o que evidencia o sentimento de uma suposta superioridade criada pelos povos brancos em relação à etnias não-brancas; no caso dos povos amarelos, uma injusta e falsa relação de colonizador e colonizado.

Assim como nos EUA, no Brasil, existiram casos de preconceito amarelo atrelados à guerra como, por exemplo, a proibição da língua japonesa na Era Vargas, com risco de ir à prisão.

Trazendo o cenário para atualidade, temos um acontecimento recente: a

xenofobia presente, fenômeno emergente, também decorrente do preconceito racial, o asian fetish,o qual, traduzido ao pé da letra, é um feitiche por asiáticos, não por "gosto" pessoal, mas pelo sentimento de objetificar uma raça considerada inferior. A "preferência sexual" por mulheres/homens não brancos está muito atrelada a estereótipos raciais que circundam o imaginário da branquitude e demarcam a diferença racial. Os estereótipos reduzem "a algumas poucas características simples e essenciais, que são representadas como fixas por natureza" (Hall, 2016, p. 190).

Stuart Hall coloca que existem três pontos a serem consideradas no ato de estereotipagem: "ele essencializa e fixa a diferença, cria um lugar de normalidade, expelindo dele qualquer coisa considerada o "Outro", e, por fim, tende a se dar onde há desigualdades de poder" (Okabayashi, 2019, p. 22). O ato de estereotipagem é também uma violência. Para ele, há uma conexão entre representação, diferença e poder" (Hall, 2016, p. 193) e, portanto, o ato de estereotipagem como uma prática representacional, 


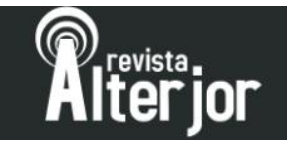

configura-se enquanto uma violência simbólica. Nesta dinâmica de desejo e poder, corpos não brancos continuam a ser vistos como um objeto para servir à branquitude.

\section{YELLOWFACE E WHITEWASHING}

Juntando todos esses fatores elencados anteriormente, é possível compreender melhor o cenário do preconceito amarelo e como ele é replicado na sociedade, nas mais diversas formas, como por exemplo, num diálogo corriqueiro, num olhar dentro do transporte público e nas telas de cinema e TV. O primeiro filme da história a incitar uma forma de preconceito asiático e utilizar o chamado yellowface foi o Terra dos Deuses (The Good Earth, 1937), o qual correu ao recurso de pintar um ator branco de amarelo, usando maquiagem para também deixar seus olhos com um aspecto mais puxado, insultando toda uma cultura e a representando de maneira imprópria.

No caso desse filme (e de todos os outros que utilizaram o recurso de yellowface) havia outras atrizes/atores asiáticos para performar e interpretar um amarelo propriamente dito, porém o cinema foi impactado pela política antimiscigenação do cinema, a que alegava que indivíduos não brancos não poderiam performar em produções televisivas.

Embora tenha passado muito tempo desde essa política, o yellowface e o whitewashing ("embranquecer" asiáticos, deslegitimando os costumes orientais) ainda são praticados em diversos filmes, novelas e séries, inclusive de grandes produtoras como a Globo que, em 2012, lançou a novela "Sol Nascente", na qual havia uma família japonesa e os atores que a performaram eram pintados e maquiados para parecerem asiáticos. Além disso, essa família permanecia constantemente em segundo plano, se fazendo desnecessária e representando de maneira altamente desrespeitosa os povos asiáticos.

\section{ANÁLISE DOS FILMES}




\section{Rerejer}

\section{Análise Filme "Bonequinha de Luxo"}

No filme Bonequinha de Luxo (Breakfast at Tiffany's 1961) é possível notar um caso de yellowface, no qual o personagem senhor Yunioshi é interpretado por um ator branco, que performa de maneira caricata e ofensiva. $\mathrm{Na}$ maioria dos casos de yellowface, os amarelos são representados de maneira rotulada e estereotipada, ou, até mesmo, não representados, como no exemplo citado. No minuto 3:58 do longametragem, o personagem é acordado pelo interfone que toca em seu apartamento. Ele desperta atordoado e bate a cabeça no lustre de seu quarto, o qual simula um cômodo tipicamente oriental, com o colchão baixo sobre o chão e a lâmpada rebaixada, além do biombo presente no ambiente. No take seguinte, o personagem indaga frases como se fossem reclamações em japonês, no entanto, elas não têm tradução, o que mostra a intenção de transformar a cena em cômica, desrespeitando os costumes, o idioma e a cor de toda uma etnia. Segundo o livro "Encanto de Narciso" de Boris Kossoy, "Trata-se de um desafio intelectual em perceber nas imagens indícios que possam nos levar a decifrar ideologias, mentalidades e padrões de comportamento, apesar de toda a carga de subjetividade inerente a tal proposta. A fotografia se refere, ao mesmo tempo, e de forma codificada e simbólica, ao invisível (o aparente) e ao invisível (o oculto)”.

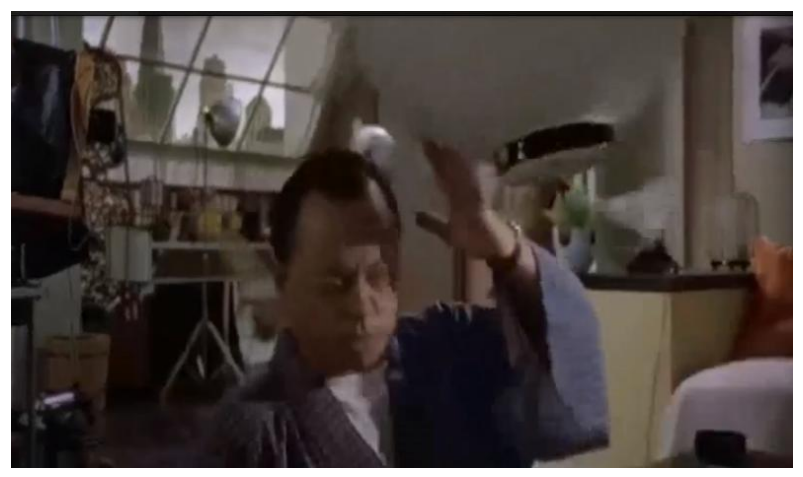

Cena do filme, minuto 3:10

A ação seguinte do Senhor Yunioshi é falar com a protagonista do filme, indagando as mesmas palavras em japonês, que não são traduzidas e se mostrando 


\section{Ditiojior}

perturbado com o barulho causado por sua vizinha. No geral, essa cena pouco acrescenta ao enredo da história, além de se mostrar altamente preconceituosa.

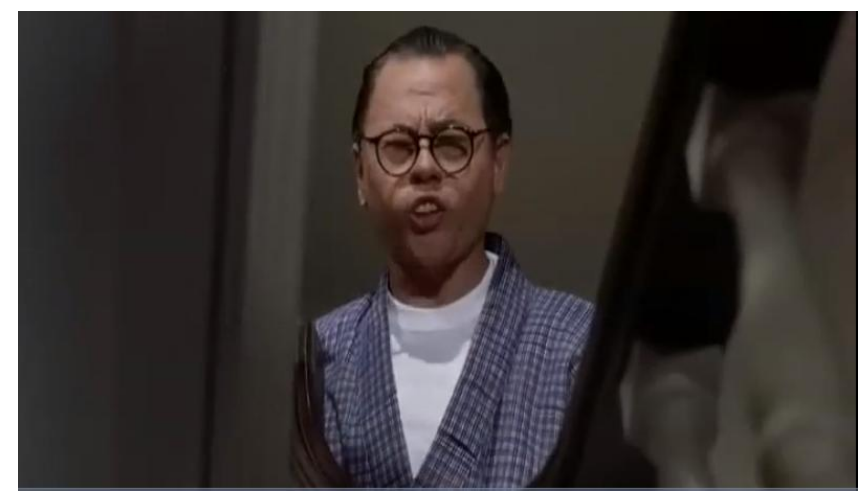

Cena do filme, minuto $3: 58$

A próxima aparição do personagem baseia-se no mesmo roteiro: ele é acordado pelo barulho na casa de sua vizinha Holly, a protagonista, e se levanta furioso, indagando a mesma palavra em japonês e pedindo para que haja silêncio, no entanto, ao voltar para seu apartamento, bate de cara com a porta, indicando mais uma vez, o desejo dos diretores de transpassar a imagem de um oriental cômico, estranho, estrangeiro, atrapalhado e principalmente, desnecessário ao discorrer da trama.

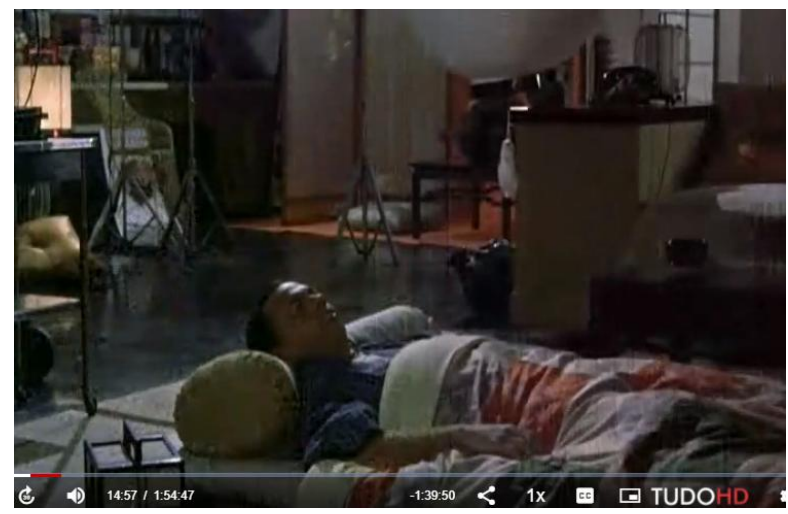

Cena do filme, minuto 14:57

\section{Revista ALTERJOR}

Grupo de Estudos Alterjor: Jornalismo Popular e Alternativo (ECA-USP)

Ano 12 - Volume 01 - Edição 25 - Janeiro-Junho de 2022

Av. Professor Lúcio Martins Rodrigues, 443, Cidade Universitária, São Paulo, CEP: 05508-020 

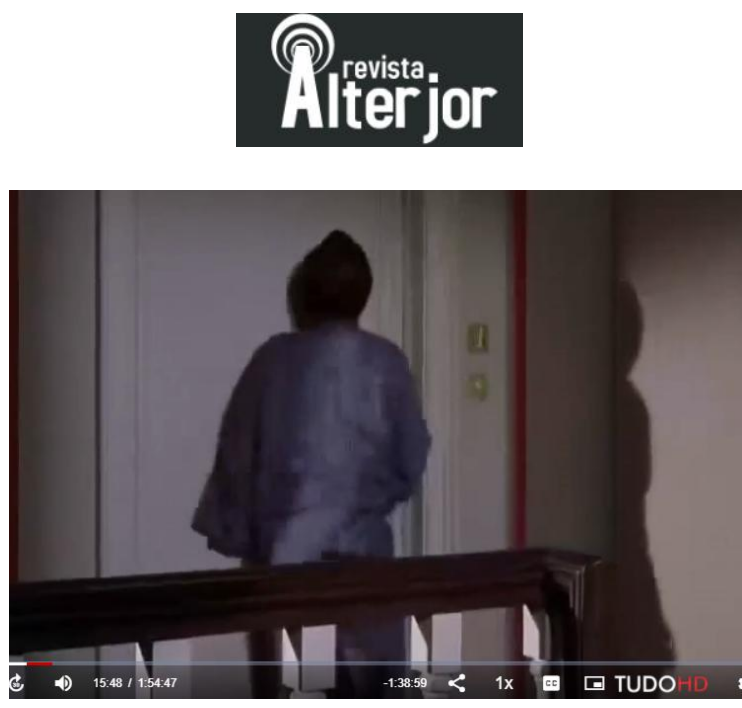

Cena do filme, minuto 15:48
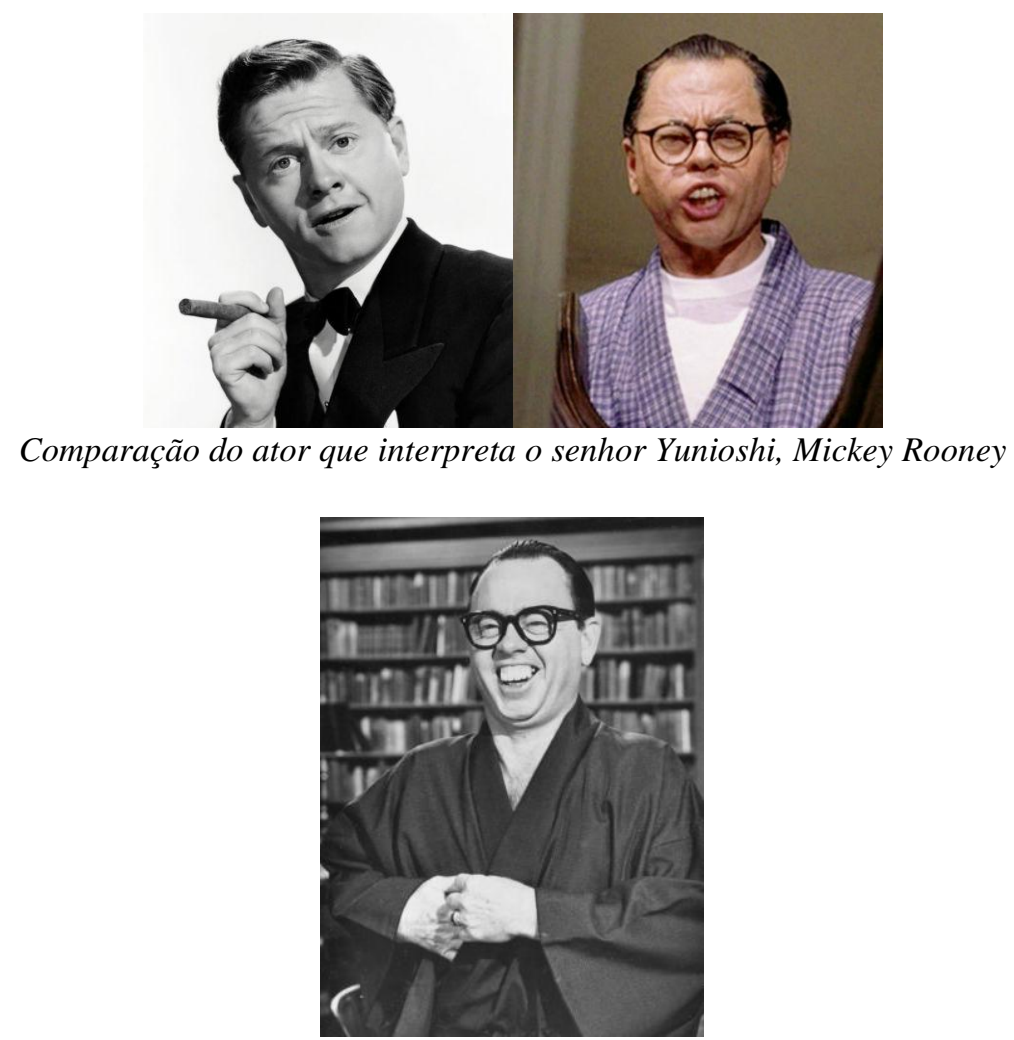

\section{Análise novela Sol Nascente}

A novela da Globo de 2016 de Walter Negrão, Suzana Pires e Júlio Fischer, Sol Nascente, foi bastante comentada na época de lançamento, por conta do ator Luís Melo, o qual foi escolhido para ser o patriarca de uma família japonesa imigrante. Apesar de a trama ter contado com atrizes de ascendência asiática como Carol Nakamura, a direção utilizou práticas de yellowface para representar um personagem asiático.

\section{Revista ALTERJOR}

Grupo de Estudos Alterjor: Jornalismo Popular e Alternativo (ECA-USP)

Ano 12 - Volume 01 - Edição 25 - Janeiro-Junho de 2022

Av. Professor Lúcio Martins Rodrigues, 443, Cidade Universitária, São Paulo, CEP: 05508-020 


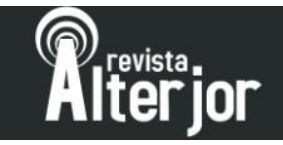

Numa nota em um site consta: "O patriarca de sua família será um ator que até tem olhos puxados: Luis Melo. Recentemente ele admitiu que é de origem indígena, daí vem esses olhos puxados; apesar de não ter feições orientais, a Globo não viu problemas de o escalar para um dos personagens principais da trama de Walter Negrão, Suzana Pires e Júlio Fischer", o que realça o gesto da direção da novela de não representar de forma digna a etnia em questão, visto que na própria novela tiveram atores de fato, asiáticos.

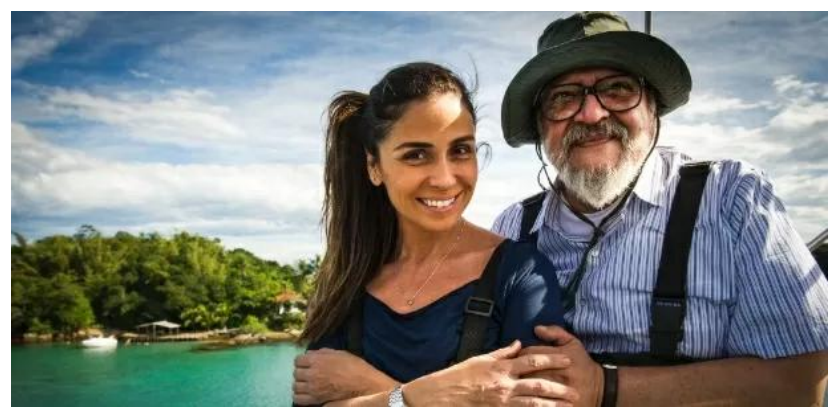

Giovanna Antonelli (Alice) e Luis Melo (Kazuo Tanaka) em "Sol Nascente"

\section{CONSIDERAÇÕES FINAIS}

Desde o começo dessa trajetória, obtive grandes aprendizados tanto pessoais quanto acadêmicos, assim como, a oportunidade também, de conhecer mais a respeito de um assunto que já me despertava grande interesse. Dessa forma, a partir do início da minha pesquisa e com todo o suporte da minha orientadora, Prof. Dra. Simonetta Persichetti e do CIP (Centro Interdisciplinar de Pesquisa), consegui desenvolver meu tema-problema e já seguir em direção aos meus objetivos, como por exemplo, projetar melhor esse assunto, por meio do podcast gravado e divulgado na página da faculdade no Spotify, o que levou várias pessoas a ouvirem e terem, talvez, o primeiro contato com esse assunto.

Além disso, me reconectei com as minhas origens e constatei, além das minhas vivências, mas principalmente a partir de estudos, quão rica é a cultura oriental. Assim,

\section{Revista ALTERJOR}

Grupo de Estudos Alterjor: Jornalismo Popular e Alternativo (ECA-USP)

Ano 12 - Volume 01 - Edição 25 - Janeiro-Junho de 2022

Av. Professor Lúcio Martins Rodrigues, 443, Cidade Universitária, São Paulo, CEP: 05508-020 


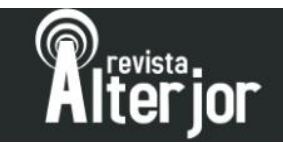

obtive maior segurança para debater sobre assuntos relacionados e, trazer essa pauta para os meus ciclos sociais, abordando-o de maneira mais assertiva.

Finalizando, acredito na evolução constante do pensamento da sociedade, visto que já existem indícios do início da representatividade das etnias asiáticas e consequentemente, maior discussão sobre essas pautas tão necessárias. Além disso, acredito que os indivíduos de ascendências mal representadas devem buscar por mais informação em relação à representatividade, apoiar produções e trabalhos feitos por pessoas dessas etnias; pesquisar mais sobre e também, produzir conteúdo científicos, uma vez que, não é facilmente encontrada uma ampla variedade de materiais acadêmicos voltados para essas questões.

\section{REFERÊNCIAS}

ADORNO, Theodor W. Indústria Cultural. São Paulo, Editora Unesp, 2016.

BURKE, Peter. Testemunha Ocular. São Paulo, Editora Unesp, 2016.

MOSCOVICI, Serge. Representações Sociais. Petrópolis, Editora Vozes, 2015.

DAROYA, Emerich. Potatoes and rice: exploring the racial politics of gay men's desires and desirability. Tese de Doutorado. Carleton University, 2011.

HALL, Stuart. Cultura e representação. Rio de Janeiro: Ed. Puc-Rio: Apicuri, 2016.

HOOKS, Bell. Olhares negros: raça e representação. São Paulo: Editora Elefante, 2019.

OKABAYASHI, Hugo Katsuo Othuki. Pornografia gay e racismo: a representação e o consumo do corpo amarelo na pornografia gay ocidental. Trabalho de Conclusão de Curso. Universidade Federal Fluminense, 2019.

LIPPMANN, Walter. Opinião Pública. Petrópolis, Editora Vozes, 2008.

KOSSOY, Boris. O encanto de Narciso: Reflexões sobre a Fotografia I - Cotia, SP: Ateliê Editorial, 2020.

Revista ALTERJOR

Grupo de Estudos Alterjor: Jornalismo Popular e Alternativo (ECA-USP)

Ano 12 - Volume 01 - Edição 25 - Janeiro-Junho de 2022

Av. Professor Lúcio Martins Rodrigues, 443, Cidade Universitária, São Paulo, CEP: 05508-020 


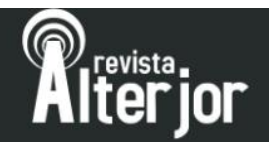

Sites:

JORNALISMO JUNIOR. Preconceito, representatividade e cultura. Disponível em: http://jornalismojunior.com.br/preconceito-representatividade-e-cultura-asiatica/. Acesso em: 19 mai. 2021.

MUNDO EDUCAÇÃO. Campos de concentração para japoneses nos EUA. Disponível em: https://mundoeducacao.uol.com.br/historiageral/campos-concentracao-para-japoneses-noseua.htm\#: :text=Ao\%20todo\%2C\%20foram\%20constru\%C3\%ADdos\%2010,Autoridade $\% 20 \mathrm{~d}$ e\%20Reloca\%C3\%A7\%C3\%A3o\%20de\%20Guerra\%E2\%80\%9D.. Acesso em: 7 jun. 2021.

OUTRA COLUNA. Representatividade e racismo na mídia brasileira. Disponível em: https://outracoluna.wordpress.com/2015/12/17/representatividade-e-racismo-na-midiabrasileira-asiansontv/ . Acesso em: 9 jun. 2021.

POLÍTICA LIVRE. Os estereótipos de Lippman e a responsabilidade do cidadão. Disponível em: https://politicalivre.com.br/artigos/os-estereotipos-de-lippmann-e-aresponsabilidade-do-cidadao/\#gsc.tab=0 . Acesso em: 3 abr. 2021. 